\title{
A Proposed Measure Of IT Infrastructure Flexibility In The Global Networked Firm: Extending The IT Infrastructure Measure Of Reach And Range
}

Kerry Ward, University of Nebraska - Omaha, USA

\begin{abstract}
In today's fast paced global business environment, firms need a flexible infrastructure that allows the organization to adapt to rapid change. An important enabler of this flexibility is the IT infrastructure. IT infrastructure flexibility is not a well understood concept and little work has been done on how to measure IT infrastructure flexibility. This paper fills this gap by proposing a measure for IT Infrastructure flexibility based on Keen's 1991 reach and range.
\end{abstract}

Keywords: IT Infrastructure Flexibility; Organizational Structure; Reach and Range

\section{INTRODUCTION}

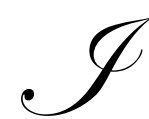

$\mathrm{n}$ order to meet the challenges of today's global business environment, firms are increasingly looking towards a networked organizational structure designed for flexibility. Essential to a firm's ability to enable this flexibility is the underlying IT infrastructure which can either enable or constrain the structure of an organization (Ives, Jarvenpaa \& Mason, 1993). The ability to understand how and when IT infrastructure enables or constrains an organization requires a way to measure this IT infrastructure flexibility.

The purpose of this paper is to propose a measure for IT infrastructure flexibility that builds on Keen's (1991) reach and range measure for IT infrastructure. Specifically this paper proposes extending Keen's reach and range measure by operationalizing it into a vertical and horizontal component. Extending reach and range to include horizontal and vertical measures will increase the measures ability to address not only the need for hybrid decision making but also to accommodate both global efficiency and local responsiveness so important in today's competitive environment.

The next section presents background information that provides support for the foundation issues and their importance. In particular, the background section provides information on the need to address both global efficiency and local responsiveness and how the emergence of the network structure allows a firm to accomplish this. How IT infrastructure can support the network structure is discussed and finally a measure is proposed for IT infrastructure flexibility.

\section{BACKGROUND}

\section{Need for Global Efficiency and Local Responsiveness}

Today's global business organizations face a business environment that can be described as increasingly complex and competitive. Some modern markets have even been described as "hypercompetitive" (Sambamurthy \& Zmud, 2000) where competitive advantage is quickly eroded or simply does not exist. While there is still a spectrum of markets with different characteristics, what is evident is that the business environment continues to become more competitive as technology and innovation allow firms to better meet the needs of the market place in increasingly shortened time frames. 
Traditionally, international firms tended to focus on either a multinational strategy that focused on local responsiveness or a global strategy that focused on global efficiency (Bartlett \& Ghoshal 1989). A multinational strategy is normally implemented when products or service need to be tailored to local markets and a firm needs to react quickly to changes in these markets. To support local responsiveness, firms tend to be structured for subunit autonomy with decentralized decision-making and little coordination by headquarters.

Alternatively, the global strategy focuses on maximizing efficiency by coordinating the firm's resources on a global scale (Bartlett \& Ghoshal, 1989). This is usually found when products can be used in several markets with little or no changes, when there are global customers or when purchasing can be performed on a global basis (Ives \& Jarvenpaa, 1991; Ives, Jarvenpaa \& Mason, 1993). Organizations focusing on a global strategy tend to be vertically structured, with a focus on a central headquarters that controls and coordinates production across the globe.

While examining these different international strategies, Bartlett \& Ghoshal (1989) noticed that the organizations that adopted either a multinational or a global strategy were also constrained by the characteristics of the strategies, keeping the companies from adapting to changing environmental conditions. A global corporation structured to maintain efficiency on a global basis could not readily adapt its globally standardized processes and products to meet the needs of any one local market because of its rigid hierarchical top-down structure. Likewise multinational firms that focus on providing the needs of local markets lacked the coordination to gain efficiency by orchestrating firm-wide production, constraining the firm's ability to compete on price.

In other words, the organizational structure, once implemented for either global efficiency or local responsiveness, lacked flexibility and inhibited the organization from adapting to changing market conditions. An important reason for the increased need for flexibility in today's world economy therefore is to allow the firm to adapt to a changing environment by enabling both responsiveness to local markets and the cost efficiencies of global coordination.

\section{The Network Structure Firm}

Consistent with this need, the global corporation evolved into a complex networked organizational structure (Malnight 1995). This networked structure is characterized by flexibility in how it operates, allowing it to maximize its markets and operational efficiencies (Cravens, Piercy \& Shipp, 1996, Ghoshal \& Nohria, 1993). Because this complex structure is designed for flexibility and can take on many forms, to understand the flexibility, it is important to examine the common characteristics that define it.

The first characteristic is horizontal versus vertical structure (Jarvenpaa \& Ives, 1994, Allen \& Pantzalis, 1996, Gurbaxani \& Whang, 1991; Ghoshal \& Bartlett, 1990). The networked structures tend to be less vertical in nature and instead, more oriented around a horizontal structure than traditional organizational forms. This horizontal structure includes both an increased number of subunits in the organization and an increased number of relationships among subunits and with other organizations, thus the "network" designation. The increase in horizontal structure facilitates coordination and collaboration that is necessary to enable flexibility (Hitt, Keats \& DeMarie, 1998).

A second characteristic is centralized versus decentralized placement of decision rights (Jarvenpaa \& Ives, 1994; Ensign, 1999; Malnight, 1995; Hitt \& Brynjolfsson, 1997; Ghoshal \& Nohria, 1993). Initially, with the increase in international firms with multiple subunits and the proliferation of information systems, organizations started to shift from centralized to decentralize decision-making. Despite this trend, there is still knowledge in a firm that is not easily transferred. Decision rights, therefore, need to be placed in the organization where there exists knowledge that cannot be transferred and not simply decentralized (Hit \& Brynjolfsson, 1997). The networked organizational structure with its increased horizontal structure thus exhibits a hybrid decision-making process that is designed for more effective decision making (Ensign, 1999; Ghoshal \& Nohria, 1993) and that enables coordination and collaboration (Hitt, Keats \& DeMarie, 1998; Ensign, 1999). 


\section{IT Infrastructure Flexibility}

Essential to a firm's ability to enable this flexibility in organizational structure is the underlying IT infrastructure. The IT infrastructure includes information technology components such as hardware and bandwidth, human interaction such as skills, knowledge, policies and standards, IT services shared across the organization, and shared applications (Weil \& Broadbent 2000). As technology advances, there has been a tendency for the definition of IT infrastructure to expand. For example, Enterprise applications (EAs) such as ERPs are shared applications that can now be considered a part of a firm's infrastructure as a shared application.

The IT infrastructure is a key enabler of the networked organizational structure because it reduces transaction costs and thus reduces the cost of providing information anywhere across the organization (Gurbaxani \& Whang, 1991). The result is information can be transferred anywhere it is needed, enabling the hybrid decision making required by the networked structure of today's global firm. The lower transaction costs also increases the ability to develop communication between subunits allowing horizontal information flows. The end result is that IT infrastructure, by reducing the cost of moving information provides a firm with greater structural flexibility (Gurbaxani \& Whang, 1991) which enables the network structured organization.

This brings us to a pivotal question: what aspects of IT infrastructure characterize flexibility? IT infrastructure flexibility can be defined as the ability of IT infrastructure to support and enable responsiveness to business requirements including innovations in business processes, organizational structure and strategy (Duncan 1995). Duncan suggests that IT infrastructure flexibility can also be defined by omission, that is, when the infrastructure constrains a firm, it is inflexible. Although Duncan conducted exploratory research into IT infrastructure flexibility, to date, no known empirical work has been conducted to support her initial work or to create operationlized measures for the construct. In the following section, a measure for IT infrastructure is proposed.

\section{A PROPOSED MEASURE}

An approach to operationalize IT infrastructure flexibility is to extend existing measures of IT infrastructure to the construct of IT infrastructure flexibility. The seminal measure of IT infrastructure is reach and range developed by Peter Keen (1991). Keen defined reach as a measure of connectedness to measure whom is connected by the infrastructure. It can include not only intra-company subunits, but inter-company relationships such as those with customers and suppliers. Range refers to the ability to share information "directly and automatically" across the IT infrastructure or as Weill and Broadbent (2000) describe it, the functionality of shared "business activities." Range addresses the shared abilities such as common standards, which allows rapid movement of information to those within the reach component.

For the purposes of measuring IT infrastructure flexibility, reach and range can be operationalized in terms of both a vertical and horizontal dimension. Vertical reach would measure the degree of vertical connectedness (top down) while horizontal reach would measure the degree of horizontal connectedness (intra and inter-company). Vertical range would measure the ability to share information top down via shared standards and infrastructure within the organization while horizontal range would provide a measure of the ability to share information via shared standards and infrastructure among subunits and inter company.

To demonstrate how vertical and horizontal reach and range would provide a beneficial measure, consider its application to the global and multinational strategies introduced above. The original measure of reach and range would not differentiate between the IT infrastructure needs of a firm implementing a global strategy versus a firm implementing a multinational strategy. With the traditional measures of reach and range, you could receive similar measures of IT infrastructure development even though their IT infrastructure needs could be substantially different.

Consider a firm focused on a global strategy. Because the focus is on central coordination and control to maximize efficiency, information needs to pass up and down vertically between headquarters and the subunits. There is less need for connectedness or shared functionality among subunits or with local suppliers and customers (i.e. horizontal reach and range). A firm that focuses on global efficiency thus needs a high level of vertical reach and range while horizontal reach and range is of less importance. 
Alternatively, a firm focused on local responsiveness will need to coordinate horizontally with local suppliers and local customers. There is little need for a global headquarters to centrally control or coordinate the subunits because each subunit has specialized needs. A multinational will likely be less concerned about shared infrastructure with its headquarters and will be more concerned about having common connectivity and common standards with its local suppliers and customers. A firm focused on local responsiveness will thus have a much higher need for horizontal reach and range but less need for vertical reach and range.

Because the original reach and range measure does not differentiate between vertical and horizontal structures, there would be no way to discriminate between the IT infrastructure needs of a multinational strategy versus a global strategy. For example, a firm that has a global strategy may have a high level of reach and range because of the high degree of connectivity and shared infrastructure flowing down from headquarters to the subunits. For the firm with a global strategy this would be an appropriate structure. Place this same IT infrastructure in a firm with a multinational strategy and it would still be measured as having high levels of reach and range. The IT infrastructure, however, would likely be inadequate to address the needs of the multinational strategy because it lacks the inter company connectivity. Differentiating vertical versus horizontal reach and range provides valuable additional information to the measure.

Operationalizing reach and range into a vertical and horizontal component also provides a way to measure the flexibility of IT infrastructure in a networked structured firm. The degree to which the firm's IT infrastructure enables the organization's need for flexibility can be measured based on the levels of vertical and horizontal reach and range. A firm that has high levels of both vertical and horizontal reach and range will be able to support a high degree of structural flexibility. IT infrastructure flexibility will enable organizational flexibility of the network structure allowing the firm to focus on varying degrees of both global efficiency and local responsiveness. High levels of vertical and horizontal reach and range will enable the transfer of information to individuals with knowledge that can't be transferred allowing the firm to place decision-rights where the decisions can best be made.

High levels of both vertical and horizontal reach and range thus represent IT infrastructure flexibility. A firm with high levels of vertical and horizontal reach and range, or high levels of IT infrastructure flexibility, will have the ability to share a substantial amount of functionality, not just with headquarters, but between subunits and other organizations. Firms with a high level of IT infrastructure flexibility will be able to quickly shift decision making rights to where ever in the organization they can be best made. The elevated capabilities of being able to communicate and share data vertically and horizontally across the firm will allow the organization to coordinate its operations on a global scale increasing efficiency throughout the firm. These vast communication abilities will also allow decisions and resources to rapidly meet the needs of local markets.

\section{CONCLUSION}

The key contribution of this measure of IT infrastructure flexibility is a better understanding of how IT infrastructure can enable the modern organization to compete in highly competitive, rapidly changing environments. The ability to gain a competitive advantage will increasingly depend on being able to rapidly deploy firm capabilities to meet the changing environment. This cannot be accomplished without the flexible structure and infrastructure to support the firm (Teece, Pisano \& Shuen, 1997; Stalk, Evans \& Shulman, 1992).

Vertical and horizontal reach and range provides a better understanding of how to measure the level of IT infrastructure required to support the structural flexibility of the today's global networked organizational form. Flexibility is a recurring theme in current strategy and organizational literature and a measure of IT infrastructure flexibility will help move research in in organizational theory and strategy as well as IT.

\section{AUTHOR INFORMATION}

Kerry Ward is an assistant professor in the Information Systems and Quantitative Analysis department at the University of Nebraska - Omaha. Kerry's research interests include IS strategy, knowledge management and research methods. His work has been published in the International Journal of Business Information Systems and the Journal of Information Systems Technology and Planning. He is a CPA with seven years' experience in 
consulting and public accounting with Deloitte and Touché and PriceWaterhouseCoopers. E-mail: kwward@mail.unomaha.edu

\section{BIBLIOGRAPHY}

1. Allen, L., and Pantzalis, C. "Valuation of the Operating Flexibility of Multinational Corporations," Journal of International Business Studies (27:4), Fourth Quarter 1996, pp 633-653.

2. Bartlett, C.A. and Ghoshal, S. "Managing Across Borders: The Transnational Solution," Harvard Business School Press, Boston, MA, 1989.

3. Broadbent, M., Weill, P., and St. Clair, D. "The Implications of Information Technology Infrastructure for Business Process Redesign," MIS Quarterly (23:2), June 1999, pp 159-182.

4. Cravens, D.W., Piercy, N.F., and Shipp, S.H. "New Organizational Forms for Competing in Highly Dynamic Environments: the Network Paradigm," British Journal of Management (7), 1996, pp 203-218.

5. Duncan, N. "Capturing Flexibility of Information Technology Infrastructure: A Study of Resource Characteristics and their Measure," Journal of Management Information Systems (12:2) 1995, pp 37-57.

6. $\quad$ Ensign, P.C. "The Multinational Corporation as a Coordinated Network: Organizing and Managing Differently," Thunderbird International Business Review (41:3), June 1999, pp 291-322.

7. Ghoshal, S., and Nohria, N. "Horses for Courses: Organizational Forms for Multinational Corporations," Sloan Management Review, Winter 1993, pp 23-35.

8. Gurbaxani, V., and Whang, S. "The Impact of Information Systems on Organizations and Markets," Communications of the ACM (34:1), January 1991, pp 59-73.

9. Hitt, L.M., and Brynjolfsson, E. "Information Technology and Internal Firm Organization: An Exploratory Analysis," Journal of Management Information Systems (14:2), Fall 1997, pp 81-101.

10. Hitt M, Keats B, DeMarie S. Navigating in the new competitive landscape: Building strategic flexibility and competitive advantage in the 21 st century. Academy of Management Executive. November 1998;12(4):22-42.

11. Ives, B., and Jarvenpaa, S.L. "Applications of Global Information Technology: Key Issues for Management," MIS Quarterly, March 1991.

12. Ives, B., Jarvenpaa, S.L., and Mason, R.O. "Global Business Drivers: Aligning Information Technology to Global Business Strategy," IBM Systems Journal (32:1), 1993, pp 143-161.

13. Jarvenpaa, S.L., and Ives, B. "Organizing for Global Competition: The Fit of Information Technology," Decision Science (24:3), 1993, pp 547-580.

14. Jarvenpaa, S.L., and Ives, B. "The Global Network Organization of the Future: Information Management Opportunities and Challenges." Journal of Management Information Systems (10:4), Spring 1994, pp 2557.

15. Keen, P.G.W. Shaping the Future: Business Design Through Information Technology Harvard Business School Press, Cambridge, 1991.

16. Malnight, T.W. "Globalization of an Ethnocentric Firm: An Evolutionary Perspective," Strategic Management Journal (16), 1995, pp 119-141.

17. Sambamurthy, V. "Business Strategy in Hypercompetitive Environments: Rethinking the Logic of IT Differentiation," in: Framing the Domains of IT Management: Projecting the Future Through the Past, R. Zmud (ed.), Pinnaflex, Cincinnati, 2000, pp. 245-261.

18. Stalk, G., Evans, P., and Shulman, L.E. "Competing on Capabilities: The New Rules of Corporate Strategy," Harvard Business Review, March-April 1992, pp 57-68.

19. Teece, D.J., Pisano, G., and Shuen, A. "Dynamic Capabilities and Strategic Management," Strategic Management Journal (18:7) 1997, pp 509-533.

20. Weill, P., and Broadbent, M. "Managing IT Infrastructure: A Strategic Choice," in: Framing the Domains of IT Management: Projecting the Future Through the Past, R.W. Zmud (ed.), Pinnaflex, Cincinnati, Ohio, 2000 . 
\begin{tabular}{ll} 
International Journal of Management \& Information Systems - First Quarter $2012 \quad$ Volume 16, Number 1 \\
\hline
\end{tabular} NOTES 